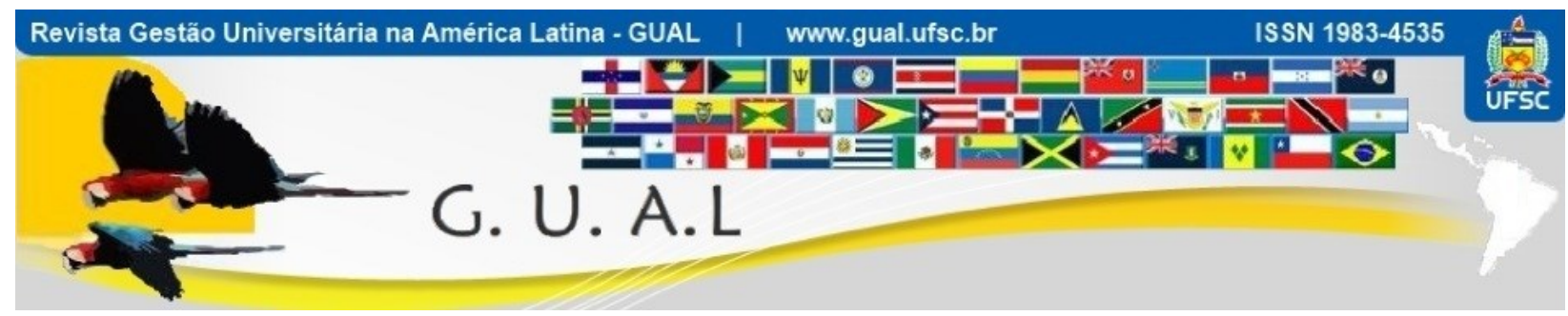

DOI: http://dx.doi.org/10.5007/1983-4535.2015v8n1p155

\title{
ANÁLISE COMPARATIVA DE RESULTADOS ECONÔMICOS: UM ESTUDO DE CASO NA PÓS- GRADUAÇÃO LATO SENSU DO CENTRO UNIVERSITÁRIO UNIVATES
}

COMPARATIVE ANALYSIS OF ECONOMIC RESULTS: A CASE STUDY IN UNIVATES GRADUATE (LATO SENSU) LEVEL

Claus Haetinger, Doutor Centro Universitário UNIVATES chaet@univates.br

Ari Künzel, Mestre Centro Universitário UNIVATES arik@univates.br

Recebido em 30/abril/2013

Aprovado em 17/dezembro/2014

Sistema de Avaliação: Double Blind Review

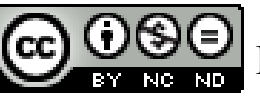

Esta obra está sob uma Licença Creative Commons Atribuição-Uso. 


\title{
RESUMO
}

Análises de resultados são importantes ferramentas auxiliares à tomada de decisões. $\mathrm{O}$ presente artigo analisa os resultados econômicos e outros indicadores decorrentes dos cursos de Pós-Graduação Lato Sensu do Centro Universitário UNIVATES, entre 2008 a 2012, à luz de quatro estruturas orçamentárias vigentes no período. Especificamente, são analisados: número de cursos concluídos, número de concluintes, margem direta, resultado econômico final, indicador de salário sobre receita e compartilhamento de disciplinas em horas. Objetivase melhorar a gestão econômico-financeira do setor, com um modelo que busque o aumento do volume de cursos de pós-graduação lato sensu, do resultado dos cursos realizados, bem como do número de profissionais atendidos por estes cursos.

Palavras-chave: Pós-Graduação lato sensu. Gestão econômico-financeira. Análise de resultados.

\begin{abstract}
Analysis of results have been important tools to decision support. This article analyzes the financial results and other indicators arising from Univates Graduate (lato sensu) curses from 2008 till 2012, based on four different budgetary structures used during this period. Specifically, there are analyzed: the number of finished courses, the number of students, the direct economic margin, the economical final result indicator on wage income, and the sharing classes in hours. The main goal has been to improve the economic and financial management sector with a model that seeks to increase the number of courses, the economical results of them, and also the number of students attended by these programs.
\end{abstract}

Keywords: Lato sensu Graduate. Economical and financial managment. Economical results analysis. 


\section{INTRODUÇÃO}

Segundo estudos apontados pela Conferência Mundial sobre Educação Superior da UNESCO (BERNHEIM e CHAUÍ, 2008), uma das principais características da sociedade contemporânea é o papel central do conhecimento nos processos de produção. Neste novo paradigma econômico e produtivo o fator mais importante deixa de ser a disponibilidade de capital, trabalho, matérias-primas ou energia, passando a ser o uso intensivo de conhecimento e informação. Atualmente, a vantagem comparativa é determinada cada vez mais pelo uso competitivo do conhecimento e das inovações tecnológicas, fazendo com que este conhecimento passe a ser um pilar da riqueza e do poder das nações, mas, ao mesmo tempo, traz uma tendência a tratá-lo meramente como mercadoria sujeita às leis do mercado. Ao se tornarem forças produtivas, o conhecimento e a informação se integram ao próprio capital, que começa a depender desses fatores para a sua acumulação e reprodução.

As organizações buscam cada vez mais maneiras de sobreviver no mercado e de se destacar entre seus concorrentes. $\mathrm{O}$ atual contexto econômico criou uma disputa acirrada por pequenas fatias de mercado, fazendo com que as Universidades disputem um a um os estudantes em potencial. Este fato gera a necessidade do aumento da eficiência no gerenciamento de seus recursos financeiros.

Uma das maneiras das Instituições de Ensino Superior (IES) colaborarem com a Sociedade do Conhecimento é qualificando profissionais por meio de cursos de pósgraduação. Ademais, segundo o Centro de Políticas Sociais da Fundação Getúlio Vargas (FGV, 2008), dentre os profissionais com Ensino Superior, aqueles que não fizeram nenhum tipo de pós-graduação ganham salário, em média, 42,1\% menor do que aqueles que a fizeram.

As Instituições Comunitárias de Ensino Superior (ICES) como o Centro Universitário UNIVATES, precisam buscar a maximização do seu valor de mercado a longo prazo, ou seja, os resultados financeiros tornam-se imprescindíveis para o seu crescimento ou mesmo manutenção, e criar instrumentos inovadores de gestão torna-se imprescindível.

A Univates exerce papel fundamental no desenvolvimento do Vale do Taquari em diversos aspectos (culturais, econômicos e sociais), haja vista que a Presidência do Conselho Regional de Desenvolvimento (COREDE) do Vale do Taquari (CODEVAT) é usualmente exercida pelo Reitor da Univates.

Neste intuito, historicamente a Univates tem elaborado e oferecido um grande número de cursos de pós-graduação lato sensu à comunidade regional do Vale do Taquari, RS. 
Contudo, a demanda de estudantes tem sido insuficiente para a viabilidade econômica de muitos deles, baseada na estimativa de margem direta definida pela IES. De outro lado, o resultado financeiro obtido com a oferta dos que se efetivam tem sido considerado aquém das expectativas da Instituição. Consequentemente, nos últimos anos foram implantadas diversas modificações na estrutura orçamentária destes cursos. Assim sendo, estima-se que, efetuando uma análise comparativa entre diversos indicadores, entre eles: número de cursos concluídos, número de concluintes, margem direta, resultado financeiro final, indicador de salário sobre receita e compartilhamento de disciplinas em horas, possa-se encontrar um conjunto de medidas que visam à indução de estratégias de controle e que auxiliem à tomada de decisões tanto para a elaboração de novos projetos de cursos, como para o aumento do volume de implantação destes e do resultado a ser obtido com a efetivação dos mesmos.

Pelo exposto, entende-se que um efetivo estudo sobre a gestão da pós-graduação lato sensu será de grande importância para a Univates, pois este setor tende a ser um dos com maior potencialidade de captação de recursos para a IES, haja vista o número crescente e diversificado de egressos formados tanto na própria Instituição, como a partir de profissionais formados em outras do Vale do Taquari e fora dele que, uma vez atuando no mercado de trabalho, percebem a necessidade de um aperfeiçoamento em nível de especialização, considerando ser a educação um fator preponderante para a melhoria da condição de vida.

Para tal, é necessário buscar diferenciais competitivos. Embora haja farta literatura sobre Contabilidade Gerencial, o desafio posto é o de encontrar um modelo que seja adequado ao contexto vivenciado por esta ICES. São poucos os estudos que relatam o uso de controle de custos em organizações prestadoras de serviços, especialmente em IES. Visto sob este prisma, o presente artigo exige um estudo sobre os diferentes modelos orçamentários para que se consiga uma aplicação por meio da implementação de ações e análise de resultados, visando também servir de motivação para outros setores da PROPEX como a Extensão, por exemplo.

Diante do contexto apresentado, o presente artigo propõe-se a analisar as diversas estruturas orçamentárias utilizadas nos últimos anos e propor um modelo para os cursos de pós-graduação lato sensu da Univates, que dê sustentação à política institucional de aumentar a inserção social da IES, buscando aumentar o número de estudantes atendidos, o volume de cursos e a melhoria do resultado econômico-financeiro do setor. 
Desta feita, o problema de pesquisa proposto configura-se da seguinte forma: Qual o impacto das diferentes Resoluções que regulamentaram os orçamentos dos cursos de PósGraduação lato sensu na Univates nos últimos anos nos resultados econômicos dos mesmos?

\section{PROCEDIMENTOS METODOLÓGICOS}

Uma organização "tem de buscar formas de viabilizar a obtenção de vantagem competitiva, identificar aspectos que permitam as organizações "ganhar os pedidos" ao invés de somente "se qualificarem" a competir pelos mesmos" (CYRNE e SANTOS, 2003, p.44).

Percebe-se uma ociosidade de vagas na maioria das turmas dos cursos de pósgraduação lato sensu da Univates, apesar das diversas estratégias de divulgação utilizadas.

Realizar modificações no modelo de gestão traz sempre implicações. Numa dimensão, busca-se entender melhor a distribuição dos custos referentes aos cursos, fazendo com que mais elementos sejam considerados, a tal ponto do resultado estimado ser o mais próximo possível do realizado. Logo, há necessidade de se trabalhar com uma margem direta mais elevada, prevendo, entre outros, possíveis desistências ao longo do curso. Em outra dimensão, busca-se uma diminuição do valor de mensalidade, para ter preços mais competitivos, além da busca por viabilização dos cursos a partir de um número pequeno de estudantes.

A Univates trabalha com dois métodos de custeio: Direto e Pleno. No primeiro consideram-se apenas os custos diretamente ligados aos cursos. Já o Custeio Pleno, considera todas as despesas e custos da IES, trabalhando com o rateio dos custos indiretos e despesas.

Estes métodos de custeio podem subsidiar decisões da Pró-Reitoria de Pesquisa, Extensão e Pós-Graduação (PROPEX) no que se refere à Pós-Graduação lato sensu: englobando a política de preços praticados, os descontos concedidos, a infraestrutura a ser disponibilizada, os investimentos a serem feitos, a oferta ou não de determinado curso, o corte de custos ou despesas, os valores de remuneração de docentes internos e externos à IES, etc.

A dúvida de qual método utilizar tem gerado discussões nesta ICES, inclusive entre a Pró-Reitoria e os coordenadores dos cursos, e, quando se aborda o Método de Custeio Pleno, discutem-se também os rateios utilizados para alocar os custos e despesas.

Com base nestas necessidades, surge este trabalho de intervenção, objetivando verificar quais as principais diferenças e aplicações para os modelos orçamentários utilizados nos últimos anos na apuração dos resultados dos cursos de pós-graduação lato sensu da Univates, sobretudo baseados em quatro Resoluções utilizadas no período de 2008 a 2012. 
A pesquisa caracteriza-se por um estudo de caso, pois conforme Malhotra (2001), é um processo que procura descrever e analisar alguma entidade em termos qualitativos, complexos e compreensivos e, não invariavelmente, como ele se desdobra em um período de tempo. Caracteriza-se por ser um método qualitativo, pois as inferências a partir dos resultados obtidos não são estatísticas (BARBETTA, 1994). Consiste na análise intensiva de poucas situações, priorizando a descrição completa e o entendimento dos fatores de cada situação (BOYD \& STASCH, apud BARBETTA, 1994). Segundo Garber (2002), o estudo de caso "[...] é caracterizado pelo estudo profundo e exaustivo de um ou de poucos objetos, de maneira que permita o seu amplo e detalhado conhecimento, tarefa praticamente impossível mediante os outros delineamentos considerados".

A busca de subsídios para este trabalho passou, além da teoria disponível, pelo estudo de dados históricos junto ao Sistema de Informações Vitais (SIV) da Univates, com auxílio do Setor de Controladoria e da Secretaria de Pós-Graduação.

Neste contexto, a Univates tem adotado princípios para a elaboração dos orçamentos dos cursos, com definição de margem direta mínima vinculada a um número mínimo de estudantes por curso. A cada semestre, surge a discussão: se determinado curso não atingiu os parâmetros mínimos definidos, o que fazer? Há defensores de que o mesmo não seja ofertado, enquanto outros defendem que, embora com número insuficiente de estudantes matriculados, a oferta auxilia na diminuição dos custos fixos do setor.

Como não existe um modelo orçamentário definitivo e inquestionável, o estudo procura detectar vantagens e desvantagens da utilização de cada um deles, comparando os resultados por meio de indicadores baseados numa série cronológica de cursos. Dessa forma pretende-se melhorar a visualização e, por conseguinte, o entendimento das implicações e resultados da adoção de cada um, respectivamente. De modo secundário, pretende-se uma melhor visualização dos custos e despesas da IES e, portanto, um maior controle sobre eles.

Considerando o primeiro autor ter estado à frente da Pró-Reitoria de Pesquisa, Extensão e Pós-Graduação no período de 2009 a 2012, o desenvolvimento deste trabalho, vinculado ao Curso de Especialização em Gestão Universitária da Univates, é de importância acadêmica, administrativa e também estratégica, trazendo uma visão sistêmica da Gestão Universitária. De outra parte, o modelo proposto servirá como uma ferramenta que visa a auxiliar a tomada de decisões, permitindo simulações em cenários diversificados. 
Este trabalho não entrará em discussões sobre critérios de rateio, pois, segundo Iudícibus (1998, p. 129 e 130), “...nunca passarão de 'razoáveis', mesmo que no senso comum apareçam como perfeitamente lógicos". Este autor mostra uma alternativa, dizendo que "Somente através de uma investigação rigorosa de fundo quantitativo, com análise de correlação e outras, poderíamos apurar critérios não excessivamente enviesados de rateio".

Destaca-se, ainda, ter sido dada autorização da Reitoria da Univates para trabalhar-se com estas informações. Os valores apresentados em reais (R\$), no presente artigo, sofreram todos conversão por uma mesma constante multiplicativa, para efeito de preservação dos dados institucionais. Contudo, por terem mantido a mesma proporção, continuam servindo como referência para o leitor, uma vez que o objetivo central do estudo é mostrar o comparativo entre um modelo adotado e outro.

\section{A CARACTERIZAÇÃO DOS CURSOS DE PÓS-GRADUAÇÃO LATO SENSU}

Neste trabalho, definiu-se por "curso de pós-graduação" os que ocorrem na Univates, presenciais, com carga horária mínima de 360 horas, usualmente com duração de 2 anos.

Busca-se aqui analisar os modelos orçamentários dos cursos de pós-graduação lato sensu da Univates, caracterizando um estudo de caso descritivo e quantitativo, baseando-se nas ideias de diversos autores, do Setor de Controladoria (COLOMBO, 2008; SILVA, 2008; COLOMBO, 2009), de professores do Curso de Contabilidade da IES, bem como do levantamento de dados e da análise em outras ICES. O levantamento de dados interno é baseado na série cronológica dos cursos iniciados entre 2006 e 2012, ou seja, por pesquisa documental. As tabelas de dados pesquisados foram desenvolvidas em Planilhas de Cálculo.

Os cursos de pós-graduação da Univates usualmente têm sua origem nos Conselhos dos Cursos regulares de graduação que propõe ao respectivo Conselho de Centro a criação dos mesmos. Uma vez recomendados pelos Centros, a análise passa a ser feita junto à Câmara de Pesquisa e Pós-Graduação, que os recomenda ao Conselho Universitário, órgão colegiado deliberativo, que os aprova ou não. As propostas de cursos regulares devem ser encaminhadas uma vez ao ano, ao final do primeiro semestre, para início no ano seguinte, independentemente desta oferta ser no primeiro ou no segundo semestre. Já os cursos na modalidade in company podem ser propostos a qualquer tempo, mediante demanda. Em ambos os casos, é feita análise do projeto do curso e do respectivo orçamento. A Instituição determina patamares orçamentários mínimos no que se refere à margem direta para a 
realização dos cursos, regulamentados por Resolução específica. Os cursos in company não serão objeto de estudo deste trabalho, nem tampouco cursos na modalidade a distância (EAD).

\section{O SISTEMA DE INFORMAÇÕES VITAIS (SIV)}

Desde o ano de 2001 a Univates elabora o Sistema de Informações Vitais - SIV. Até meados de 2005 esse sistema não utilizava critérios de rateio de custos indiretos, ou seja, trabalhava-se apenas com a margem direta dos cursos. A partir de então começou-se a elaborar uma planilha de retorno sobre o investimento, sendo necessário definir critérios para ratear os custos indiretos, bem como os investimentos necessários para todos os cursos. Durante certo tempo, esses critérios de rateio de custos indiretos geraram muitas discussões, em função do grau de arbitrariedade embutido em qualquer uma das formas a ser utilizada. No entanto, após as discussões, foram consolidados os critérios e são utilizados até hoje.

A partir do ano de 2009, foi instituída uma área específica para elaboração de orçamentos de cursos novos, projetos, serviços, etc. Inicialmente procurou-se apresentar nestes orçamentos os custos específicos (diretos), além de uma previsão de custos indiretos totais, utilizando os critérios de rateio estipulados no cálculo do retorno sobre o investimento.

Atualmente está em discussão a especificação nos orçamentos dos custos das secretarias, separados dos demais custos indiretos. Isso porque entende-se que esses custos (de secretarias específicas) são específicos para determinado grupo de cursos ou projetos. Para a apuração dos mesmos estão sendo discutidos novos critérios. A princípio, levantou-se os custos específicos de cada secretaria (extensão, pesquisa, ou pós-graduação) e conversou-se com os envolvidos diretos de cada área para identificar e melhor direcionar os respectivos custos. Em alguns casos, optou-se pelo total de turmas oferecidas, em outros, pelo total de horas-aula oferecidas, conforme a quantidade de trabalho que cada curso gera para as secretarias. Contudo, não há consenso quanto a atribuir todos os custos aos cursos oferecidos nos casos em que ocorre ociosidade. Para evitar este problema, estão sendo levantadas as capacidades máximas de oferta de cursos (número de turmas ou horas oferecidas), para que o custo total da secretaria seja dividido pela sua capacidade instalada, determinando de modo mais detalhado o custo a ser atribuído a cada curso.

Destaca-se que o SIV surgiu quando a Univates apresentava um crescimento de $30 \%$ ao ano no seu número de estudantes e ocorria a criação de muitos novos cursos, especialmente na graduação. Além disso, a alteração da personalidade jurídica da Instituição (de órgão 
público para empresa privada sem fins lucrativos), levou à necessidade de implantação de um SI que permitisse identificar as receitas, despesas e o resultado dos setores e cursos da Instituição, disponibilizando-os aos responsáveis para auxiliar na tomada de decisão, com o objetivo de melhorar seus resultados.

Esperava-se envolver todos os gestores dos diversos níveis, para que as informações fossem disseminadas em toda a organização. Para isso, inicialmente foram realizadas reuniões mensais com Coordenadores dos Setores, dos Cursos, Diretores de Centro e Reitoria. Com o passar dos meses, percebeu-se que as reuniões tornavam-se repetitivas e o grupo muito grande, já que o ciclo operacional da Instituição é semestral, ou seja, seu número de estudantes e demais indicadores apresentam poucas variações durante o semestre. Em função disso, passaram-se a realizar reuniões mensais somente com a Reitoria e Diretores de Centro.

O SIV é disponibilizado parcialmente a todos os gestores da IES, no que se refere ao respectivo setor, para auxiliar no processo de tomada de decisão. Sua estruturação é feita pelo Setor de Controladoria, especialmente pelas áreas de Custos e Orçamentos e Financeiro.

A Reitoria acompanha o desempenho da IES por intermédio deste sistema. As informações apresentadas subsidiam as decisões relacionadas à abertura ou ao fechamento de novos cursos, realização de investimentos e acompanhamento de metas definidas no orçamento anual. Os Diretores de Centro e Coordenadores de Cursos são estimulados pela Reitoria a utilizarem as informações do SIV na gestão de suas áreas. Além de ser uma ferramenta que possibilita melhorias na gestão dos cursos e setores, serve para avaliar o seu desempenho. $\mathrm{O}$ alcance das metas estabelecidas direciona as decisões de novos investimentos.

O SIV da Univates apresenta a estratificação e organização das informações econômicas e financeiras de toda Instituição em forma de planilhas eletrônicas, divididas em quatro grandes perspectivas: comercial, econômica, financeira e operacional. O SIV econômico hoje encontra-se no Business Intelligence System (BI).

A perspectiva comercial apresenta informações relacionadas ao número de acadêmicos matriculados, créditos matriculados, inscrições no vestibular, entre outros. Essas informações são separadas por Cursos, Centros e tipo de matrícula (graduação, cursos técnicos, extensão e pós-graduação), para serem comparadas com a previsão orçamentária.

Já a perspectiva econômica apresenta as receitas e despesas por centro de custos (Cursos e Setores), Centros e Pró-Reitorias. A margem de contribuição de cada Curso é apresentada em valor e percentual, e comparada com a previsão orçamentária e com períodos 
anteriores. As informações são apresentadas de forma detalhada, por centros de custos, e também de forma aglutinada, por Centros e Pró-Reitorias. O retorno sobre o investimento é calculado para cada curso regular da IES. As margens brutas são acumuladas para identificar a representatividade de cada Curso.

Essas informações permitem a identificação dos cursos que apresentam maior rentabilidade e também daqueles cujo resultado ou margem não são os esperados. A análise do Resumo da Demonstração do Resultado por Curso permite identificar quais são e no que incorrem os custos mais significativos, auxiliando a busca de ações para sua redução.

A perspectiva financeira, por sua vez, apresenta a composição dos valores a receber e dos financiamentos contraídos, separados por origem e vencimento. O fluxo de caixa integra o SIV financeiro e apresenta as informações passadas e previsões futuras de entradas e saídas. A análise dessas informações auxilia no planejamento financeiro a curto e a longo prazo, no sentido de definir ações para redução da inadimplência, políticas de cobrança e identificar necessidade de obtenção de novos financiamentos. Apresenta ainda a previsão de projetos de investimentos a serem realizados, comparando-os com o que já foi executado no período.

A perspectiva operacional do SI apresenta a alocação de horas de docentes por Curso e por atividades. Essa informação permite avaliar a distribuição de tarefas e atividades e o cálculo da média de estudantes por sala de aula por Curso, possibilitando o remanejamento das atividades e a otimização das horas dedicadas às atividades acadêmicas (sala de aula e coordenação), pesquisa e extensão. Também permite a avaliação da distribuição entre horas de professores horistas e em tempo integral.

Todos os dados do SIV provêm dos sistemas contábil e acadêmico. Após a elaboração dos demonstrativos pelo Setor Contábil, os dados são apresentados em reuniões aos grupos anteriormente citados. A prática está focada na gestão econômico-financeira da Instituição, buscando aumento das receitas, diminuição das despesas e investimentos rentáveis.

Uma consultoria externa acompanhou o processo de implantação do SIV por aproximadamente dois anos. Após esse período, constatou-se que a prática estava consolidada e a manutenção passou a ser responsabilidade da área de Custos e Orçamentos, vinculada à Controladoria. A avaliação do SIV é feita mensalmente, quando são identificadas novas necessidades e sugeridas melhorias no sistema, o que ocorre em praticamente todas as reuniões, como a descrita acima que se refere ao rateio dos custos das secretarias específicas 
Os benefícios do sistema são intangíveis, porém extremamente relevantes, uma vez que não é possível quantificar monetariamente melhorias na tomada de decisão e gestão. A Instituição apresenta hoje uma situação econômico-financeira estável e seus indicadores de liquidez e rentabilidade são satisfatórios.

Uma gestão eficiente dos recursos disponíveis permite aumento na capacidade de investimento, o que resulta em melhoria na infraestrutura ofertada aos acadêmicos (laboratórios, equipamentos, salas de aula confortáveis e climatizadas, oferta de crédito educativo próprio, entre outros). Ademais, as informações disponibilizadas permitem avaliar os Cursos em sua individualidade, possibilitando a adoção de ações específicas com o objetivo de reter os estudantes atuais e obter novos. Como exemplos citam-se a criação de uma linha específica de crédito rotativo para Cursos de Licenciatura e a concessão de descontos nas disciplinas de estágios dos Cursos da área da Saúde, além de descontos da ordem de 50\% na mensalidade de cada disciplina que o acadêmico eventualmente reprovar.

Antes da implantação do sistema, havia demanda por parte dos Coordenadores, que tinham grande dificuldade em avaliar o desempenho de seu Curso sob a ótica financeira e econômica, haja vista que estas atividades de Coordenação são temporárias, e nem todos os docentes possuem formação ou treinamento prévio na área de gestão. Da mesma forma, a Reitora demandava grande número de informações que não estavam prontamente disponíveis ou eram de difícil obtenção, o que implicava em demora no processo decisório. Após a implantação do sistema, percebeu-se satisfação por parte dos Coordenadores de Cursos, Setores e Reitoria, que, além de utilizarem as informações disponibilizadas, com frequência apresentam novas demandas. Anteriormente à esta implantação, os Coordenadores focavam sua atenção exclusivamente para os aspectos acadêmicos. Inicialmente, houve alguma resistência para que assumissem o seu papel administrativo, o que só foi possível em função da mudança de cultura estimulada pela Reitoria.

O SIV está em constante aperfeiçoamento na quantidade e qualidade de informações disponibilizadas e na sua operacionalização, tanto que implantou-se recentemente um sistema de Business Intelligence - BI, para centralizar as informações e agilizar a sua disponibilização, sob diversos prismas, para os diferentes usuários. Isso tem reduzido o tempo de preparação das informações, que passam a ficar disponíveis de forma instantânea a todos os gestores. 


\section{ANÁLISE COMPARATIVA DE RESULTADOS ECONÔMICOS: UM ESTUDO DE CASO NA PÓS- \\ GRADUAÇÃO LATO SENSU DO CENTRO UNIVERSITÁRIO UNIVATES \\ DOI: http://dx.doi.org/10.5007/1983-4535.2015v8n1p155}

\section{AS ESTRUTURAS DOS RESULTADOS}

Para a melhor compreensão das descrições e análises subsequentes, apresentam-se a seguir as estruturas de resultados adotados pela Univates em relação aos cursos de pósgraduação lato sensu.

A Univates adotou a seguinte estrutura dos resultados para os que iniciaram até 2010:

Tabela 1 Estrutura dos resultados - cursos que iniciaram até 2010.

\begin{tabular}{|l|l|}
\hline Receitas & Receitas direta ou indiretamente obtidas em decorrência dos serviços prestados. \\
\hline (-) Cancelamentos e Trancamentos & Receita não efetivada em função de trancamento de matrículas. \\
\hline = Receita Líquida & Descontos ou abatimentos concedidos aos alunos. \\
\hline (-) Descontos Concedidos & Gastos perfeitamente identificados ao curso e que alteram em função do número de alunos. \\
\hline (-) Gastos Variáveis & Gastos perfeitamente identificados ao curso e que não alteram em função do número de alunos. \\
\hline = Margem de Contribuição & \\
\hline (-) Gastos Fixos Diretos & Gastos indiretos, não podem ser identificados ao curso. \\
\hline = Margem Direta & \\
\hline (-) Gastos Fixos Indiretos & Resultado do Curso
\end{tabular}

Fonte: Controladoria da Univates.

A partir de 2011, adotou-se nova estrutura, a saber:

Tabela 2 Estrutura dos resultados - cursos que iniciaram a partir de 2011

\begin{tabular}{|l|l|}
\hline Receita Bruta & Receitas direta ou indiretamente obtidas em decorrência dos serviços prestados. \\
\hline (-) Cancelamentos e Trancamentos & Receita não efetivada em função de trancamento de matrículas \\
\hline (-) Descontos Concedidos & Descontos concedidos \\
\hline = Receita Líquida & Gastos perfeitamente identificados ao curso e que alteram em função do número de alunos. \\
\hline (-) Gastos Variáveis & Gastos perfeitamente indentificados ao curso e que não alteram em função do número de alunos. \\
\hline = Margem de Contribuição & Bolsa de um semestre de Interlinguas concedida para alunos da pós-graduação. \\
\hline (-) Gastos Fixos Diretos & Margem Direta 1 \\
\hline (-) Interlínguas & Gastos com secretaria, considerando somente os cursos que efetivamente ocorreram. \\
\hline = Margem Direta 2 & (-) Gastos Secretaria 1
\end{tabular}

Fonte: Controladoria da Univates.

Entende-se que os termos constantes nas Tabelas 1 e 2 sejam suficientemente autoexplicativos.

Aprovada pelo Conselho Universitário (CONSUN) em 20 de julho de 2006, a Resolução 062/Reitoria/Univates (UNIVATES, 2006) aprovou a forma de remuneração para docência em cursos de pós-graduação lato sensu. Os principais pontos desta Resolução foram: 


\begin{tabular}{|l|l|}
\hline \multicolumn{1}{|c|}{ Enquadramento } & \multicolumn{1}{c|}{ Remuneração proposta na resolução } \\
\hline Professor visitante & $\begin{array}{l}1,894 \% \text { do salário hora do TC/40 (Tempo } \\
\text { Contínuo 40 horas - Assistente Nível I; }\end{array}$ \\
\hline Professor Doutor TC do quadro docente & até 2,8 vezes o valor do Titular Nível III \\
\hline Professor Doutor horista & $90 \%$ do valor do Doutor TC; \\
\hline Professor Mestre TC & até 2,8 vezes o valor do Adjunto Nível III \\
\hline Professor Mestre Horista & até $90 \%$ do Mestre TC \\
\hline Professor Especialista TC & até 2,8 vezes o valor do Assistente Nível III \\
\hline Professor Especialista TC & $90 \%$ do Especialista TC \\
\hline Hora de orientação & $72 \%$ da hora aula \\
\hline
\end{tabular}

Quadro 01 Enquadramento e remuneração resolução 062/Reitoria/Univates/2006.

Fonte: Controladoria da Univates.

A resolução previa ainda a possibilidade de remuneração diferenciada para casos especiais de docentes reconhecidos por notório saber. Os docentes TC podiam optar por incluir a docência na pós-graduação na carga horária do seu contrato de trabalho recebendo (1) uma hora de preparação para cada hora lecionada. Para as orientações a remuneração proposta previa um valor correspondente a $72 \%$ da hora aula de cada professor de acordo com seu enquadramento. A resolução previa uma margem de contribuição mínima de 33,33\%, que nenhum professor orientasse mais do que $35 \%$ dos estudantes, o desconto de $30 \%$ nas mensalidades para funcionários quando atingido o número de 2 estudantes a mais do que o mínimo estipulado no projeto do curso e também a possibilidade da PROPEX recomendar o oferecimento de cursos abaixo desta margem mínima, mediante aprovação do CONSUN.

No vigor desta Resolução, foram concluídos 9 cursos, com uma média de 23 matriculados, sendo o mínimo de 11 e o máximo de 41, a margem direta média foi de 36,96\%, sendo a mínima de $-17,09 \%$ (negativo) e a máxima de $61,39 \%$, o resultado direto médio foi de $\mathrm{R} \$ 50.800,00$, sendo o mínimo de $-\mathrm{R} \$ 10.205,00$ (negativo) e o máximo de $\mathrm{R} \$ 150.733,00$, o resultado final médio foi de $-\mathrm{R} \$ 738,00$ (negativo), sendo o mínimo de $-\mathrm{R} \$ 34.584,00$ (negativo) e o máximo de $\mathrm{R} \$ 59.864,00$.

As receitas e o resultado apresentaram o seguinte comportamento: a receita líquida média foi de $\mathrm{R} \$ 137.565,00$, sendo a mínima de $\mathrm{R} \$ 59.716,00$ e a máxima de $\mathrm{R} \$ 245.546,00$; a receita líquida total foi de $\mathrm{R} \$ 1.238 .085,00$; o resultado direto total foi de $\mathrm{R} \$ 457.200,00$.

A participação do custo de salário sobre receita apresentou uma média de 49,22\%, sendo o mínimo de $30,71 \%$ e o máximo de $79,71 \%$ e o compartilhamento de disciplinas entre os cursos, que reduz os custos com salários apresentou uma média $18 \mathrm{hs}$, sendo o mínimo de 0 e o máximo de 56 horas. 


\section{ANÁLISE COMPARATIVA DE RESULTADOS ECONÔMICOS: UM ESTUDO DE CASO NA PÓS- GRADUAÇÃO LATO SENSU DO CENTRO UNIVERSITÁRIO UNIVATES \\ DOI: http://dx.doi.org/10.5007/1983-4535.2015v8n1p155}

Na prática, os Coordenadores de Curso, quando do encaminhamento das propostas de cursos, obrigatoriamente previam o atingimento da meta de margem de contribuição de $33,33 \%$, ajustando o número de estudantes de tal modo que a mesma fosse atingida, e com preços bastante reduzidos. Isto fazia com que cursos fossem enviados para aprovação com indicativo de número mínimo de estudantes muitas vezes excessivo, e que posteriormente não se verificava. Cabia então, caso a caso, à PROPEX analisar com o respectivo Coordenador de Curso, alternativas. Estas alternativas implicavam, via de regra, em redução do valor da horaaula extra a ser paga aos docentes (retirando a isonomia), redução da carga horária de Coordenação, e diminuição da margem de contribuição. Assim sendo, após todo o desgaste da negociação, autorizava-se, em geral, a oferta destes cursos. Considerando ainda as desistências ao longo do curso, alguns concluíam com margem de até 8\%.

Para piorar, num novo lançamento do curso, por ser reedição, o orçamento indicado pelo Coordenador não previa aumento significativo das mensalidades, nem aumento do número mínimo de estudantes, pressionando a PROPEX para aprovar nova edição nos mesmos patamares baixos da anterior.

Com o intuito de modificar-se este panorama, elaborou-se, em 2008, a Resolução 137/Reitoria/Univates de 06 de novembro de 2008. Esta Resolução foi aprovada pelo CONSUN em 06 de novembro de 2008 (UNIVATES, 2008), e trouxe algumas modificações importantes que seguem:

\begin{tabular}{|l|l|}
\hline \multicolumn{1}{|c|}{ Enquadramento } & \multicolumn{1}{c|}{ Remuneração proposta na resolução } \\
\hline Professor visitante Doutor & $\begin{array}{l}\text { entre 2 ao máximo } 5 \text { vezes o valor hora-aula do } \\
\text { Adjunto G do novo plano de pessoal. }\end{array}$ \\
\hline Professor visitante Mestre & entre 2 ao máximo 5 vezes o valor do Assistente G \\
\hline Professor visitante Especialista & entre 2 ao máximo 5 vezes o valor do Auxiliar G \\
\hline $\begin{array}{l}\text { Professor Doutor QDC (quadro de } \\
\text { Carreira Docente) }\end{array}$ & até 2X o valor da hora-aula do Adjunto G \\
\hline Professor Mestre QDC & até 2X o do Assistente G \\
\hline Professor Especialista QDC & até 2X o do Auxiliar G \\
\hline Orientação para Visitantes e do QDC & remuneração de 8 horas aula por orientando \\
\hline $\begin{array}{l}\text { Orientação para QDC - inclusão no } \\
\text { Plano de trabalho }\end{array}$ & $\begin{array}{l}30 \text { minutos por orientando por semana por um } \\
\text { semestre }\end{array}$ \\
\hline
\end{tabular}

Quadro 02 Enquadramento e remuneração resolução 137/Reitoria/Univates/2008.

Fonte: Controladoria da Univates.

As remunerações previstas no Quadro 02 foram previstas para turmas de até 15 estudantes efetivamente matriculados e cursantes da respectiva disciplina. Para os cursos que 
se viabilizassem com mais que 15 estudantes foi atribuída uma gratificação de $2 \%$ por estudante a partir do $16^{\mathrm{o}}$, limitando-se o acréscimo em até $50 \%$.

A resolução definiu a carga horária destinada a Coordenação do Curso a ser definida semestralmente, com base no número de estudantes regularmente matriculados no início do semestre vigente, observando-se os seguintes critérios:

\begin{tabular}{|l|l|}
\hline Número de estudantes & \multicolumn{1}{c|}{ Carga horária } \\
\hline De 15 a 19 & até 240 horas (até $2 \mathrm{~h} 15 \mathrm{~min}$ por semestre durante 4 semestres). \\
\hline De 20 a 24 & até 260 horas (até 2h30min por semestre durante 4 semestres). \\
\hline De 25 a 29 & até 280 horas (até 2h45min por semestre durante 4 semestres); \\
\hline De 30 em diante & até 300 horas (até 3hs por semestre durante 4 semestres). \\
\hline
\end{tabular}

Quadro 03 Carga horária de coordenação resolução 137/Reitoria/Univates/2008.

Fonte: Controladoria da Univates.

A remuneração do Coordenador observou o seu enquadramento no Plano de Carreira Docente vigente e o registro da respectiva carga horária do Coordenador podia ser lançada no plano de trabalho a partir do semestre da apresentação da proposta do curso, a título de adiantamento por parte do Centro. Caso o curso fosse implementado, a PROPEX ressarcia o Centro do respectivo valor.

A resolução permitiu que fosse reduzida a exigência do percentual da margem de contribuição, aceitando-se como padrão um mínimo de $25 \%$, calculado para um número mínimo de 15 estudantes e manteve-se a possibilidade de remuneração diferenciada, a título de caso especial, para docentes reconhecidos por notório saber, porém passaram a ser analisados pela Comissão Permanente de Pessoal Docente (CPPD). As demais disposições foram mantidas.

Objetivou-se, com esta Resolução, reduzir o valor a ser pago aos docentes, com o intuito de poder viabilizar mais cursos e com um número mínimo menor de estudantes. A remuneração base passou a ser 2 vezes o valor máximo da categoria em que se enquadrava o professor conforme sua titulação, mas na faixa mais elevada $(\mathrm{G})$. Também optou-se por remunerar de forma diferenciada, sob forma de bônus, àqueles cursos que obtivessem um maior número de matriculados. A intenção foi de que, desta forma, ter-se-ia um controle atualizado das desistências ao longo do curso, ajustando o orçamento constantemente a este novo número. Da mesma forma, a carga horária do Coordenador passou a ser vinculada ao número de estudantes que permaneciam matriculados no curso. 
$\mathrm{Na}$ vigência desta Resolução, foram concluídos 18 cursos (100\% de aumento); a média de matriculados foi de 15 (representando apenas 65\% da média anterior), sendo o mínimo de 8 (73\% do anterior) e o máximo de 22 (54\% do anterior); o resultado direto médio foi de $\mathrm{R} \$ 36.708,00$ (72\% da anterior), sendo o mínima de $\mathrm{R} \$ 2.218,00$ (positivo) e o máximo de $\mathrm{R} \$ 92.010,00$ (61\% da anterior); o resultado final médio foi de $\mathrm{R} \$ 2.102,00$ (positivo), sendo o mínimo de -R $\$ 37.316,00$ (negativo) e o máximo de $\mathrm{R} \$ 43.252,00$ (72\% do anterior).

A receita líquida média foi de $\mathrm{R} \$ 107.688,00$ (78\% da Resolução anterior), sendo a mínima de $\mathrm{R} \$ 55.545,00$ (93\% da anterior) e a máxima de $\mathrm{R} \$ 193.906,00$ (79\% da anterior); a margem direta média foi de 34,09\% (92\% da anterior), sendo a mínima de 3,35\% (positiva) e a máxima de 47,45\% (77\% da anterior); a receita líquida total foi de $\mathrm{R} \$ 1.938 .384,00$ (57\% maior que a da anterior); o resultado direto total foi de $\mathrm{R} \$ 660.744,00$ (45\% maior de a anterior).

A participação dos salários sobre receita média foi de $55,25 \%$ (12\% a mais que o anterior), sendo o mínimo de $44,37 \%$ (44\% a mais) e o máximo de $80,46 \%$ ( $1 \%$ a mais) e o compartilhamento de disciplinas em horas médio foi de $10 \mathrm{hs}$ ( $56 \%$ do anterior), sendo o mínimo de 0 e o máximo de 52 horas ( $93 \%$ do anterior).

Esta Resolução apresentou grande resistência por parte do corpo docente: por um lado, os valores de remuneração foram considerados muito baixos, o que não os estimulava a trabalhar como hora extra e a propor novos cursos; de outro lado, a gratificação por número de estudantes foi considerada injusta, pois o professor da disciplina seguinte sentia-.se prejudicado caso após a disciplina do professor da disciplina anterior, o estudantes desistisse do curso. Além disso, como todos os cursos foram previstos com número mínimo de 15 matriculados, não houve um esforço extra no sentido de recrutar um número maior de estudantes. Finalmente, como o intuito era o de viabilizar mais cursos, os preços foram diminuídos consideravelmente e a margem de contribuição reduzida de 33,33\% para 25\%.

De qualquer modo, atingiu-se o objetivo de aumento do número de cursos (100\%), o resultado direto mínimo passou a ser positivo, a receita líquida total aumento em $57 \%$ e o resultado direto total aumentou em 45\%. Contudo, como houve a modificação simultânea de diversas variáveis, não foi possível aferir o real impacto de cada qual neste processo.

Todavia, em função da insatisfação do corpo docente, em 2010 passou-se para a Resolução 152/Reitoria/Univates de 28 de outubro de 2010. Autorizada pelo CONSUN em 
28 de outubro de 2010, a Resolução (UNIVATES, 2010) apresentou as seguintes modificações:

\begin{tabular}{|l|l|}
\hline \multicolumn{1}{|c|}{ Enquadramento } & \multicolumn{1}{c|}{ Remuneração proposta na resolução } \\
\hline Professor visitante Doutor & $\begin{array}{l}\text { Entre 2 ao máximo 9 vezes o valor hora-aula do } \\
\text { Adjunto G do novo plano de pessoal. }\end{array}$ \\
\hline Professor visitante Mestre & Entre 2 ao máximo 8 vezes o valor do Assistente G \\
\hline Professor visitante Especialista & Entre 2 ao máximo 7 vezes o valor do Auxiliar G \\
\hline $\begin{array}{l}\text { Professor Doutor QDC (quadro de } \\
\text { Carreira Docente) }\end{array}$ & $\begin{array}{l}\text { Remuneração como hora extra, com 50\% de acréscimo } \\
\text { para as duas primeiras e 100\% para as demais horas } \\
\text { semanais. Exceto de horista. }\end{array}$ \\
\hline Professor Mestre QDC & Idem \\
\hline Professor Especialista QDC & Idem \\
\hline Orientação para Visitantes & Remuneração de até 15 horas aula por orientando \\
\hline $\begin{array}{l}\text { Orientação para QDC - inclusão no } \\
\text { Plano de trabalho }\end{array}$ & $\begin{array}{l}\text { Remuneração de até 15 horas aula por orientando e } \\
\text { inclusão facultativa no plano de trabalho. }\end{array}$ \\
\hline
\end{tabular}

Quadro 04 Enquadramento e remuneração resolução 152/Reitoria/Univates/2010.

Fonte: Controladoria da Univates.

A negociação sugerida é no âmbito do orçamento total do curso, cabendo ajustes conforme a necessidade de ajuste da margem de contribuição. $\mathrm{O}$ valor da hora-aula do professor permanente foi conforme o seu respectivo enquadramento no Plano de Carreira Docente vigente, podendo alocar as horas-aula no seu Plano de Trabalho semestral somente com autorização expressa da Reitoria.

A carga horária de Coordenação passou a ser definida semestralmente, com base no orçamento, variando de 2 a 4 horas semanais por até 4 semestres, com valor da remuneração observando o enquadramento no Plano de Carreira Docente vigente, retirou-se a gratificação por número de estudantes e a remuneração diferenciada por notório saber continuou possível, porém agora decidida pela PROPEX, Coordenação da Pós-Graduação e Coordenação do Curso. A resolução permitiu uma remuneração diferenciada para cursos na modalidade in company, especificadas em contrato.

A maior modificação proposta por esta resolução foi, sem dúvida, a questão de que as horas-aula tivessem que ser, obrigatoriamente, remuneradas como hora-extra, além da maior variação de valores possíveis para o pagamento dos docentes visitantes.

Nesta modalidade, ainda não tivemos cursos concluídos, de modo que as análises a seguir são baseadas nos dados do SIV de novembro de 2012, e o número de estudantes dos cursos programados para 2013 é o orçado, aprovado pelo CONSUN. 
Com base nesta Resolução, estão em andamento 16 cursos, além de outros 4 programados para 2013. A média de matriculados, incluindo os dos cursos programados, está em 20 (aumento de 33\% em relação ao modelo anterior), sendo o mínimo de 9 (13\% a mais) e o máximo de 31 (41\% a mais), considerando os dados atualizados até outubro de 2012.

A margem direta não faz sentido aqui, por não ter-se cursos efetivamente concluídos. Por exemplo, os gastos com orientação ainda não foram lançados, valendo a mesma observação para o resultado final, direto e receita líquida, para o indicador de salário sobre receita. Há valores parciais apurados mas, para efeito de análise, certamente iriam distorcer os resultados.

O compartilhamento de disciplinas em horas médio, considerando somente os cursos em andamento, está em $24 \mathrm{hs}$ (140,6\% a mais que o anterior), sendo o mínimo de 0 e o máximo de 72 horas ( $38 \%$ a mais), este indicador tende a aumentar, pois nem todas as disciplinas dos cursos em andamento foram ofertadas até o presente momento.

O número de estudantes tende a ter uma pequena redução no desenrolar dos cursos, como de praxe ocorre nesta modalidade.

Os dados parciais do SIV mostram que este modelo tende a trazer uma maior margem direta e maior resultado do que a Resolução anterior.

Novamente, por terem sido modificadas diversas variáveis simultaneamente, não é possível caracterizar o impacto de cada uma delas individualmente no resultado dos cursos. Um exemplo é o fato de que houve uma dedicação maior, quando do planejamento dos cursos, para a busca de efetivo compartilhamento de disciplinas.

Em 30 de julho de 2012, aprovou-se a Resolução 096/Reitoria/Univates (UNIVATES, 2012), que se encontra em vigor no momento propôs o que segue:

\begin{tabular}{|l|l|}
\hline \multicolumn{1}{|c|}{ Enquadramento } & \multicolumn{1}{c|}{ Remuneração proposta na resolução } \\
\hline Professor visitante Doutor & $\begin{array}{l}\text { Entre 2 ao máximo 9 vezes o valor hora-aula do } \\
\text { Adjunto G do novo plano de pessoal. }\end{array}$ \\
\hline Professor visitante Mestre & Entre 2 ao máximo 8 vezes o valor do Assistente G \\
\hline Professor visitante Especialista & Entre 2 ao máximo 7 vezes o valor do Auxiliar G \\
\hline $\begin{array}{l}\text { Professor Doutor QDC (quadro de } \\
\text { Carreira Docente) }\end{array}$ & $\begin{array}{l}\text { Remuneração como hora extra, com 50\% de acréscimo } \\
\text { para as duas primeiras e 100\% para as demais horas } \\
\text { semanais de acordo com plano de carreira vigente. } \\
\text { Máximo 4 vezes o valor do adjunto G. }\end{array}$ \\
\hline Professor Mestre QDC & Idem, e Máximo 4 vezes o valor do assistente G. \\
\hline Professor Especialista QDC & Idem, e Máximo 4 vezes o valor do auxiliar G. \\
\hline Orientação para Visitantes & Remuneração de até 15 horas aula por estudante \\
\hline
\end{tabular}




\begin{tabular}{|l|l|}
\hline & $\begin{array}{l}\text { orientando, 7 horas pagas no aceite e 8 horas na entrega } \\
\text { do trabalho de conclusão. }\end{array}$ \\
\hline $\begin{array}{l}\text { Orientação para QDC - inclusão no } \\
\text { Plano de trabalho }\end{array}$ & $\begin{array}{l}\text { Remuneração de até 15 horas aula por orientando e } \\
\text { inclusão facultativa no plano de trabalho. }\end{array}$ \\
\hline
\end{tabular}

Quadro 05 Enquadramento e remuneração resolução 152/Reitoria/Univates/2010.

Fonte: Controladoria da Univates.

A resolução fez alguns ajustes e estabeleceu que nenhum professor pode receber menos do que a remuneração mínima e o valor a mais é caracterizado como gratificação. Não podem ser pagos valores diferentes para docentes do curso que possuem a mesma titulação, ou seja, há isonomia por titulação em cada curso. Em relação à Coordenação de Curso, permite pagar horas para a elaboração do Projeto Pedagógico do Curso, sendo até 40 horas para cursos novos e até 20 horas para cursos reeditados. Como gratificação, o Coordenador receberá 30 horas, após a efetiva confirmação do curso. Esta confirmação dá-se a partir da análise da margem de contribuição e do número mínimo de matriculados tendo como parâmetro o orçamento aprovado. Além disso, a carga horária do Coordenador de Curso varia entre 2 e 4 horas semanais por até 4 semestres, não podendo ultrapassar 12 horas semestrais para toda edição do curso, podendo ser registradas no orçamento 324 horas, no máximo.

Com base nesta Resolução, foram ofertados 8 novos cursos para início em 2013, bem como 4 que são reoferta, uma vez que não fecharam turma em 2012. Destes 12 , somente 5 efetivamente foram implantados (o que representa 31\% do número de cursos da resolução anterior).

A média de matriculados destes cursos programados, estava prevista em 22 (aumento de $10 \%$ em relação ao modelo anterior, caso todos se efetivassem conforme a previsão), sendo o curso com menor número de estudantes previsto para 19 (111\% a mais) e o curso com maior número mínimo previsto para 25. Na prática, dos 5 cursos efetivamente implantados, a média ficou em 16,8 estudantes por turma ( $84 \%$ da Resolução anterior), com mínimo de 9 (mesmo número da Resolução anterior) e máximo de 26 estudantes (83\% do máximo da Resolução anterior).

Os indicadores margem direta, resultado final, resultado direto, receita líquida, salário sobre receita não são conhecidos ainda, por não ter-se cursos efetivamente concluídos, assim como ainda não é possível determinar o percentual de compartilhamento de disciplinas. 


\section{CONCLUSÕES}

De modo bastante objetivo, a Resolução 137/Reitoria/Univates (UNIVATES, 2008) mostrou-se, até o presente momento, a mais adequada aos objetivos institucionais, uma vez que aumentou o número de cursos em $100 \%$, o resultado econômico direto mínimo passou a ser positivo, a receita líquida total aumento em $57 \%$ e o resultado econômico direto total aumentou em 45\%, se comparados com a Resolução 062/Reitoria/Univates (UNIVATES, 2006). Junte-se a isto o fato de ter-se praticado valores menores para as mensalidades e a diminuição da margem mínima de contribuição para a oferta dos cursos de 33,33\% para 25\%.

Caso os 4 cursos prorrogados, baseados na Resolução 152/Reitoria/Univates (UNIVATES, 2010) efetivamente se confirmassem, seria possível que este modelo ultrapassasse o anterior em número de estudantes atingidos, o que seria um ganho institucional enquanto inserção. Além disso, como houve uma preocupação quando do planejamento do conjuntos dos cursos em haver um maior compartilhamento de disciplinas, este aspecto certamente ultrapassaria os índices da Resolução anterior. Contudo, considerando o maior valor a ser pago em remuneração docente, não há como garantir que, sob o ponto de vista financeiro, os resultados econômicos deste modelo serão melhores do que o anterior. $\mathrm{O}$ número baixo de cursos efetivamente implantados, bem como o pequeno tamanho de cada turma, é outro indicativo da dubiedade do desempenho da atual Resolução.

Já a Resolução 096/Reitoria/Univates (UNIVATES, 2012) não teve tempo hábil de ser implementada por completo na prática, o que impossibilita alguma conclusão até que os cursos tenham sido encerrados, ou seja, até o final de 2014. Todavia, verifica-se uma queda acentuada no número de cursos propostos, a priori, bem como dos efetivamente implantados. Nestes, o número médio de matriculados também diminuiu até o presente momento.

De qualquer modo, não obstante os descontentamentos de um grupo de docentes por buscarem uma maior complementação de renda, a Resolução 137/Reitoria/Univates (UNIVATES, 2008) mostrou-se efetiva.

Sugere-se, como modelo ideal, uma adaptação no modelo da Resolução 137/Reitoria/Univates (UNIVATES, 2008), com valor mínimo (base) de remuneração docente sendo o de 2 vezes o valor nominal do professor (ou seja, incluindo seus triênios e quadriênios), e que a remuneração variável, a título de bonificação, seja efetivada segundo o número de matriculados no início do curso, ao invés de considerar cada disciplina. Da mesma forma, que se junte a isto o modelo da Resolução 096/Reitoria/Univates (UNIVATES, 2012) 
no que se refere ao pagamento do Coordenador do Curso, parte adiantado e outra parte caso o curso seja implementado.

\section{AGRADECIMENTOS}

Os autores agradecem o apoio e a colaboração da Pró-Reitoria Administrativa, na pessoa do Pró-Reitor Oto Roberto Moerschbacher; do Setor de Controladoria, nas pessoas das colegas Ane Josiele da Silva, Fabíola Colombo, Sandra Auler e Tailana Juchum; bem como da Coordenação de Pós-Graduação Lato Sensu, na pessoa da Coordenadora Carolina Scherer.

\section{REFERÊNCIAS}

BARBETTA, Pedro A. Estatística aplicada às ciências sociais. Florianópolis: Editora UFSC, 1994.

BDR - Banco de Dados Regional do Centro Universitário UNIVATES, 2010, http://www.univates.br/files/files/univates//bdr/Perfil_VT_Abril_2010.pdf, acesso em $18 / 05 / 2010$.

BERNHEIM, Carlos T.; CHAUÍ, Marilena de S. Desafios da Universidade na Sociedade do Conhecimento: cinco anos depois da Conferência Mundial sobre Educação Superior. Brasília: UNESCO, 2008.

BRASIL, 1943. Consolidação das Leis Trabalhistas. Decreto-Lei no. 5452, de 1o. de maio de 1943. Brasília/DF, http://www.planalto.gov.br/ccivil 03/decreto-lei/del5452.htm, acesso em $19 / 12 / 2012$.

COLOMBO, Fabíola. Estudo de custeio direto e pleno na apuração dos resultados dos cursos regulares do Centro Universitário UNIVATES. Lajeado/RS, Trabalho de Conclusão de Curso de Administração, 2008, cópia impressa.

COLOMBO, Fabíola; AULER, Sandra M. Estudo dos métodos de custeio direto e pleno na apuração dos resultados dos cursos regulares de uma Instituição de Ensino Superior. Revista Destaques Acadêmicos, ano 1, n. 1, CGO, 2009, 43-53.

CONSELHO REGIONAL DE CONTABILIDADE DO ESTADO DE SÃO PAULO. Custos: Ferramenta de Gestão. São Paulo: Atlas, 2000.

CYRNE, Carlos C. da S. SANTOS, Carlos H. S. Cinco indicadores de desempenho e empresas

certificadas ISO 9000 no Vale do Taquari. Lajeado: Univates, Estudo e Debate, 2003. Volume $10 \mathrm{n}^{\circ} 1$.

FGV. Centro de Políticas Públicas da Fundação Getúlio Vargas. http://cps.fgv.br/, acesso em dezembro de 2008. 
GARBER, R. Inteligência competitiva. São Paulo: Madras, 2002.

IUDÍCIBUS, Sergio de. Contabilidade Gerencial. 6 ed. São Paulo: Atlas, 1998.

MALHOTRA, N. K. Pesquisa de Marketing: uma orientação aplicada. 3. ed. Porto Alegre: Bookman, 2001. p. 720.

Scientific Electronic Library Online - SciELO. Disponível em:

$<$ http://www.scielo.br/scielo.php/script_sci_home/lng_pt/nrm_iso $>$ Acesso em: 01 de março de 2008.

SILVA, ANE JOSIELE DA. Orçamento empresarial de longo prazo aplicado à Univates. Lajeado/RS. Trabalho de Conclusão de Curso de Ciências Contábeis, 2008, cópia impressa, $149 \mathrm{p}$.

SUMA ECONÔMICA. Contablidade e Controle de Custos (Dissertação de Mestrado). Rio de Janeiro: Cop Grafica, 2005.

UNESCO: A Universidade na encruzilhada. Em Seminário Universidade: por que e como reformar? Brasília, 6-7 ago, 2003. Brasília: UNESCO Brasil, Ministério da Educação, 2003.

UNIVATES, 2006. Resolução 062/Reitoria/Univates. Lajeado/RS, 20 de julho de 2006, cópia impressa, $3 \mathrm{p}$.

UNIVATES, 2008. Resolução 137/Reitoria/Univates. Lajeado/RS, 06 de novembro de 2008, cópia impressa, $4 p$.

UNIVATES, 2010. Resolução 152/Reitoria/Univates. Lajeado/RS, 28 de outubro de 2012, cópia impressa, $3 p$.

UNIVATES, 2012. Resolução 096/Reitoria/Univates. Lajeado/RS, 30 de julho de 2012, cópia impressa, $4 \mathrm{p}$. 